\title{
Relational Aggression in Preschool Students: An Exploration of the Variables of Sex, Age, and Siblings
}

\author{
Karen A. Morine, ${ }^{1}$ Laura M. Crothers, ${ }^{2}$ James B. Schreiber, ${ }^{3}$ \\ Jered B. Kolbert, ${ }^{2}$ Tammy L. Hughes, ${ }^{2}$ and Ara J. Schmitt ${ }^{2}$ \\ ${ }^{1}$ Allegheny Intermediate Unit, 475 East Waterfront Drive, Homestead, PA 15120, USA \\ ${ }^{2}$ Department of Counseling, Psychology, and Special Education, Duquesne University, 600 Forbes Avenue, Pittsburgh, PA 15282, USA \\ ${ }^{3}$ Department of Educational Foundations and Leadership, Duquesne University, 600 Forbes Avenue, Pittsburgh, PA 15282, USA
}

Correspondence should be addressed to Laura M. Crothers, crothersl@duq.edu

Received 14 July 2011; Accepted 8 September 2011

Academic Editor: Xinyin Chen

Copyright (c) 2011 Karen A. Morine et al. This is an open access article distributed under the Creative Commons Attribution License, which permits unrestricted use, distribution, and reproduction in any medium, provided the original work is properly cited.

In this study, researchers wished to ascertain whether there were age (three- and four-year old), sibling (with or without older siblings), and sex (male and female) differences in the use of relational aggression in preschool students as rated by peers and teachers. In order to answer this research question, two $2 \times 2 \times 2$ factorial ANOVA procedures with the relational aggression composite score as the dependent variable on the PSBS-P and PSBS-T were used for peer and teacher assessment, respectively, of relational aggression. Results revealed that in the peer ratings of preschool students' relationally aggressive behavior, there was an disordinal age by sibling interaction, in which four-year-old children with siblings were significantly more likely to be rated by their peers as using relational aggression than three-year-old children without siblings. In the teacher ratings of preschool students' relationally aggressive behavior, a main effect for age was observed. Teachers rated four-year old children as evidencing significantly higher levels of relational aggression as compared to three-year-olds. No sex differences were observed in the use of relational aggression either at age three or age four in this sample. Implications for these findings are presented.

\section{Introduction}

Numerous studies have revealed that youth who use and/or are victims of relational aggression are at higher risk for psychological and social adjustment problems than those not involved in relationally aggressive conflicts (e.g., [1-3]). In the research literature, relational aggression is frequently characterized as the intent to harm another through the exploitation of a relationship [4]. Relational aggression is defined in terms of its endpoint, which is to manipulate or disrupt relationships and friendships [5], and is often carried out in front of a victim, for example, a girl telling her friend that they will no longer be friends unless she does what the girl wants [6]. Other researchers have used the term indirect aggression to describe such behaviors, which in contrast to relational aggression, is defined in relation to the covert, "behind the back" form the aggression takes [5]. Indirect aggression is thought to be a more covert behavior, whereas relational aggression does not have to be covert. Finally, social aggression is a concept very similar to both relational and indirect relational aggression [6]. It encompasses all the forms of behavior described for relational and indirect aggression and includes harmful nonverbal behavior, such as eye-rolling and giving dirty looks [5]. Researchers using the three labels disagree over which term is the most useful for describing these manipulative forms of behavior. Archer and Coyne [5] conclude that the behaviors described by the terms, indirect, relational, and social aggression are much more similar than they are different.

To date, most of the research on relational aggression has focused upon school-age youth, particularly adolescents. This is likely partly due to the fact that relational aggression has been typically portrayed as being more characteristic of girls than boys, and the predominant theories of the development of aggression suggest that behavioral problems amongst girls are unlikely to appear until early adolescence $[7,8]$. 
Indeed, although relational aggression tends to be more prevalent in the school age years and beyond due to children's cognitive abilities and social networks $[9,10]$, researchers have found that preschoolers also use relational aggression, although in a less sophisticated manner [11-15]. In comparison to other forms of aggression, relatively little is known about the etiology of relational aggression [16], and the impact of sex, age, and sibling status upon preschoolers' experience with relational aggression is not clearly understood.

Consistent with the reality that the variables of bullying and age have not been exhaustively investigated, it was once thought that preschool-age boys and girls both began using physical aggression to bully others because they lacked the social and language skills to be relationally aggressive [17, 18]. However, more recent studies have revealed that children as young as two and a half years of age have been found to display relational aggression [19] while those three to five years old are able to recognize relational aggression in one another [18]. While the incidence of relational aggression in preschoolers has been documented, the relationship between age and relationally aggressive behavior has not been elucidated. Although older children appear to use relational aggression more than younger children $[9,10]$, the existing research has not been able to document why and at what rate this increase occurs.

Sibling relationships have recently begun to receive increased empirical focus as a potential contributor to the development of relational aggression. Siblings provide for many children the first opportunities for socialization, and research indicates that the influence of sibling relationships is distinct from that of parents. Bank et al. [20] found that characteristics of sibling relationships are significant predictors of future psychological adjustment even after controlling for the impact of parents. Social learning and coercion theories suggest that children learn social behaviors, including aggression, and relational styles within family relationships, which they then use with friends and peers [21,22]. Studies indicate that social cognitive skills, which are considered by some to be necessary in order to engage in relational aggression, are more likely to be evident earlier in sibling interactions than in peer interactions (e.g., [23]), which supports the idea that children first use and learn relational aggression in sibling relationships.

The limited research regarding the role of siblings in the use of relational aggression amongst preschool-age children suggests that this is an important area of inquiry. Stauffacher and DeHart [24] found that relational aggression occurred more frequently during the interactions of preschoolers and their siblings than in preschoolers' interactions with their friends. Furthermore, Stauffacher and DeHart [16] noted that during the preschool age, while children frequently engaged in relational aggression directed at their siblings but used little relational aggression with their friends, by middle childhood, the opposite pattern was observed, with the same children using more relational aggression towards their friends and little relational aggression directed towards their siblings. Ostrov et al. [25] discovered that older siblings'
TABLE 1: Description of the sample by gender, ethnicity, and age.

\begin{tabular}{lcc}
\hline Gender & $N$ & $\%$ \\
Male & 36 & $54.5 \%$ \\
Female & 30 & $45.5 \%$ \\
Total & 66 & $100 \%$ \\
\hline Ethnicity & $N$ & $\%$ \\
Caucasian & 59 & $89.4 \%$ \\
African-american & 4 & $6.1 \%$ \\
Other & 3 & $4.5 \%$ \\
Total & 66 & $100 \%$ \\
\hline Age & $N$ & $\%$ \\
3-years-old & 28 & $42.4 \%$ \\
4-years-old & 38 & $57.6 \%$ \\
Total & 66 & $100 \%$ \\
\hline
\end{tabular}

relational aggression was associated with younger siblings' use of relational aggression towards peers.

The present study also examined sex differences amongst preschoolers. Although relational aggression is often presented as more characteristic of girls and physical aggression more typical of males (e.g., [17]), the research literature is mixed. Archer's [26] meta-analysis of sex differences for different forms of aggression revealed that these differences are moderated by the method of assessment, such as parent report, teacher report, self report, or behavior observation.

\section{Method}

2.1. Participants. The participants of the study consisted of 68 three- and four-year-old male and female children enrolled in preschool programs in southwestern Pennsylvania. Because two parents requested that their children not participate in the peer assessment of relational aggression, the responses from these individuals were subsequently deleted from the final dataset. Tabachnick and Fidell [27] suggest that this procedure be employed when there are few cases with missing data, and the cases are a random portion of the whole sample. Consequently, the study included 66 total participants (see Table 1 for description of sample).

\subsection{Instruments}

2.2.1. Preschool Social Behavior Scale-Teacher Form (PSBS-T). The social behavior of the preschool participants of the study was evaluated through teacher and peer ratings. Accordingly, the Preschool Social Behavior Scale-Teacher Form (PSBS-T) was used in order to assess teachers' perceptions of preschool students' social behavior [12]. This measure was adapted from a previous teacher rating measure, the Children's Social Behavior Scale-Teacher Form (CSBS-T), constructed by Crick [28]. The PSBS-T is a questionnaire consisting of 25 items with four scales: (1) relational aggression, (2) overt/ physical aggression, (3) prosocial behavior, and (4) depressed affect. Eight items assess relational aggression, 8 assess overt aggression, 4 assess prosocial behavior, and 3 assess depressed affect. Teachers rate each child on a scale from 1 (never or 
almost never true of this child) to 5 (always or almost always true of this child). For the purposes of this research, only the relational aggression subscale was used from this measure.

Procedures to classify children as relationally aggressive were followed according to those used in past research [11]. Teacher-assessed scores were used to identify extreme groups of relationally aggressive and relationally nonaggressive children. Children with relational aggression scores greater than one standard deviation above the sample mean were classified as relationally aggressive, and those with scores below one standard deviation were classified as nonrelationally aggressive.

The reliability of the PSBS-T is high, with Cronbach's alpha for the four scales as follows: $\alpha=.96$ (relational aggression), .94 (overt aggression), .88 (prosocial behavior), and .87 (depressed affect). Crick et al. [12] performed a principalcomponents factor analysis to determine if relational aggression is indeed a separate factor from overt aggression. Results indicated high factor loadings for relational aggression, ranging from .81 to .89 . The validity of the measure has not yet been documented in a published study.

2.2.2. Preschool Social Behavior Scale-Peer Form (PSBS-P). Crick and colleagues [12] developed the Preschool Social Behavior Scale-Peer Form (PSBS-P), a measure that provides an assessment of peer reports of preschoolers' use of relational aggression, overt aggression, and prosocial behavior. This measure was also adapted from a previous assessment instrument developed in prior research with elementary school children [17]. The PSBS-P uses a picture nomination procedure to elicit the child's opinion of his or her peers' tendency to use relational aggression.

During the picture nomination interview, children are asked to point to pictures of participating children in his or her classroom, such as "Point to the pictures of three children who you like to play with" and "Point to the pictures of three children who whisper mean things about other children." The measure consists of 19 items and contains the following 3 subscales: (1) peer acceptance, (2) peer rejection, and (3) relational aggression. Seven items assess relational aggression, 7 assess overt aggression, and 4 assess prosocial behavior. For the purposes of this research, only the relational aggression subscale was used from this measure.

The PSBS-P was scored according to the procedures outlined by Crick and Grotpeter [17]. As such, the number of nominations each participating child receives from peers was summed for each item and then standardized within each classroom to account for differences in class size. All child's standardized scores were then aggregated to yield a total relational aggression score.

The reliability coefficients for the PSBS-P are satisfactory, with Cronbach's alpha for the three scales as follows: $\alpha=.71$ (relational aggression), .77 (overt aggression), and .68 (prosocial behavior). Results of a principal-components factor analysis with varimax rotation indicated moderate factor loadings for peer reports of relational aggression, ranging from .64 to .76 , confirming that relational aggression as assessed by peers is a separate factor from overt aggression [12].
As with the PSBS-T, the validity of this measure has not yet been documented in a published study.

2.3. Procedure. Upon receiving approval from the principal author's Institutional Review Board (IRB), the researchers identified preschools within a county in southwestern Pennsylvania using the Pennsylvania Department of Public Welfare Keystone Stars listing available via the internet. Seventeen childcare facilities were contacted, and eight of the facilities participated in the research. The researcher contacted the director of each preschool by phone or E-mail to explain the nature of the study as well as assess his or her interest in participating. Upon receiving approval from the preschool director, the researcher provided the director with a packet of information to distribute to parents of all three- and fouryear-old children at their childcare center. The packet included a letter explaining the nature of the study in addition to written consent forms. Parents of prospective participants then returned a signed consent form to their child's teacher or center director.

After written parent permission was received, the researcher supplied each participating child's classroom teacher with a written consent form. At this time, the researcher reviewed the assessment procedures to be used with each individual child. Prior to the administration of the individualized assessments, the researcher met individually with each participating child to discuss the nature of the study as well as to allow for the child to provide assent for participation in the study. One hundred percent of the participating children provided their assent. The individual assessments were conducted in an unoccupied room or in a quiet area of the classroom.

Preschool teachers were provided with written and verbal instructions regarding how to complete the PSBS-T. Participating teachers completed one rating scale per each participating child, and if there was more than one teacher per classroom, such individuals completed the measure together to ensure a shared perspective of behavior. Because preschool classrooms often have more than one teacher, researchers recommend that teachers complete the measure as a group to encourage the compilation of the most accurate information about each child [12].

The PSBS-P, a picture-nomination procedure, was used during an interview with each participating preschool student. The primary investigator photographed each participant, who was subsequently presented with pictures of each participating child in the classroom and was asked to name each child. These procedures encouraged participants to consider the entire class of children before responding to the items as well as to confirm that the child recognized the children in his or her classroom. Next, the child was presented with several practice items in order to help him or her learn the response format of the measure. The child was shown pictures of three common food items (e.g., carrots, cookies, and apples) and was asked to point to his or her most preferred food, followed by the next preferred, and finally, to the food item least preferred. When the child understood the response format, the examiner continued with the behavioral items of the PSBS-P. 
TABLE 2: Means and standard deviations for emotion knowledge and relational aggression across depressed affect groups.

\begin{tabular}{lccccc}
\hline & \multicolumn{2}{c}{ Emotion knowledge } & \multicolumn{2}{c}{ Teacher RA } & \multicolumn{2}{c}{ Peer RA } \\
& $M$ & SD & $M$ & SD & SD \\
\hline Depressed affect & 48.22 & 7.52 & 12.06 & 5.41 & -.265 \\
Non-depressed affect & 48.75 & 7.82 & 9.52 & 4.76 & .855 \\
\hline
\end{tabular}

For each item, the researcher asked the child to point to up to three pictures of peers who matched the behavioral descriptor (i.e., point to the picture of a child who whispers mean things about other children, and point to a picture of one more child who whispers mean things about other children, point to one more child who whispers mean things about other children). The number of nominations each child received from classmates for each item was computed and then standardized within each classroom using $z$-scores in order to account for differences in the number of children in the classrooms.

\section{Results}

In this study, researchers wished to ascertain whether there were age (three- and four-year old), sibling (with or without older siblings), and sex (male and female) differences in the use of relational aggression in preschool students as rated by peers and teachers. In order to answer this research question, a $2 \times 2 \times 2$ factorial ANOVA with the relational aggression composite score as the dependent variable was used for peer assessment of preschool students' relationally aggressive behavior. A second factorial ANOVA was conducted using the Relational Aggression composite scores from the teacher assessment of preschool students' relationally aggressive behavior. A MANOVA was not chosen because the scores only have $10 \%$ of variance in common. For this analysis, alpha was set at a .05 level of significance. Table 2 displays the means and standard deviations for emotion knowledge and relational aggression across depressed affect groups.

First, a strong, positive correlation was found between peer and teacher ratings of relational aggression $(r=.82)$. Subsequent inferential analyses revealed that in the peer ratings of relational aggression, there was a disordinal age by sibling interaction, $F(1,66)=5.69, P=.02$, with an effect size of partial $\eta^{2}=.09$. Essentially, four-year old children with siblings were significantly more likely to be rated by their peers as using relational aggression than three-year old children without siblings. In the teacher ratings of relational aggression, we observed a main effect for age, $F(1,65)=4.87$, $P=.03$, with an effect size of partial $\eta^{2}=.08$. Teachers rated four-year-old children as evidencing significantly higher levels of relational aggression as compared to three-year-olds. No sex differences were observed in the use of relational aggression either at age three or age four in this sample.

\section{Discussion}

Consistent with findings documented in the previous literature (e.g., $[11,12,14,15,25])$, the research in the current study found that both teachers and peers identified relational aggression in the three- and four-year-old preschool children. When considering these groups separately, this study found that teachers and peers both rated four-year-olds as significantly more relationally aggressive than three-yearolds. Furthermore, four-year-old children who had siblings were significantly more likely to be rated by their peers as using relational aggression than three-year-old preschool students who did not have siblings. However, there were no differences between male and female preschool students' use of relational aggression at either age three or four.

Although there is some evidence that older children use relational aggression to a greater degree than younger children (e.g., [25]), previous research has not yet fully examined age differences in preschool students' use of relational aggression. The current findings reveal that the incidence of relational aggression in preschool students is noticeably greater at age four than at age three. These results may be due to differences in cognitive abilities and increasing social and emotional competence. For example, Crick and Rose [30] contend that relational aggression may intensify as children grow older due to a growing sophistication in their cognitive abilities and an increasing understanding of complex social networks. Although the variables of age and relational aggression are not entirely understood, there is evidence to suggest that in contrast to other forms of aggression, which tend to decrease with age (e.g., physical aggression [30]), the use of relational aggression increases with the age of the child.

These findings are also consistent with previous research in which one study showed that relational aggression is the most frequently used form of aggression that siblings use towards each other, which may influence the opportunity for the learning of such behaviors within the family environment [11]. In addition, research with three- and four-year-old siblings who were assessed for relational aggression using a structured observation technique indicated that female older sisters were more likely to use relational aggression toward female peers than their younger female sisters [25], suggesting that female children become more expert in the use of relational aggression as they age.

The findings of this research may exemplify Bandura's [31] social cognitive theory, in which it is postulated that aspects of an individual's knowledge acquisition can be directly related to observing others within the context of social interactions and experiences. In this case, it is likely that children with siblings have acquired relationally-aggressive behavior through modeling the behavior demonstrated by these siblings. In fact, researchers have documented that social cognitive skills may be observed earlier in sibling interactions than in peer interactions (e.g., [23]), suggesting that sibling relationships may be one of the first social contexts in which children demonstrate relational aggression [16]. 
Features of sibling relationships during early childhood that are conducive to the demonstration of relational aggression include the amount of time spent together, a shared history, opportunities for a shared range of contexts and experiences, and a high level of intimacy [16]. In a study of 4-year-old children, some with younger and some with older siblings, Stauffacher and DeHart [16] found high levels of relational aggression observed between siblings, while comparatively little relational aggression was used by these children with their peers.

4.1. Contributions of This Research. The current findings are important as they build on the extant literature showing that teachers and peers can identify relational aggression in young children (e.g., $[11,12,14,15,25])$, as young as two and a half years of age [19]. As such, reported concerns of relational aggression from either of these groups should be taken seriously by parents and teachers and correspondingly, both children and teachers should be consulted when caregivers are considering intervention in these behaviors. Furthermore, the results of this study enhance the literature by highlighting the importance of considering sibling relationships in the context of observed relational aggression (e.g., [25]). This study suggests that for those who are attending to the behaviors of young children, there are several opportunities to intervene with relationally aggressive preschoolers (e.g., in the home, school, and community settings). For example, discussions with parents about sibling interactions, especially those between female siblings, provide an opportunity for teaching and rewarding prosocial interactions in the home [25].

It is important to mention that in this study, no differences in use of relational aggression were found based on sex. In general, the differences in the use of relational aggression based on sex in the extant literature base are mixed. Our findings add to the research demonstrating that this is not a consistently reliable variable needed to understand relational aggression in preschoolers (e.g., $[16,32,33])$.

A unique contribution of this study is the differences in relational aggression documented between the threeand four-year olds. In our sample, the four-year olds were significantly more relationally aggressive as rated by teachers and peers. These findings, in light of work by Casas et al. [19] showing that children as young as two and a half years of age display relational aggression, and the conclusions by Ostrov and colleagues [25] that behavioral patterns are well established by the end of the preschool period, come together to highlight that between ages three and four there likely is a significant increase in the use of relational aggression. Optimally, then, interventions targeting relational aggression should be in place by the age of three [25].

4.2. Conclusions and Future Directions. Based upon this and other research on this topic, there is an accumulation of evidence that during the preschool period, likely before the age of three, the first opportunities to decrease the use of relational aggression exist. Parents, who are aware of sibling conflicts, and particularly their children's use of relational aggression, should be advised to seek intervention services as relational aggression tends to increase across the developmental period if unchecked. Otherwise, it is likely that the use of relational aggression with siblings will continue on with peers (e.g., $[16,25])$. Researchers have noted that relationally aggressive peer interactions become similar in type and frequency to relationally aggressive sibling interactions when children reach middle childhood (e.g., age eight; [16]).

There are several limitations of the current study to consider in light of the findings. First, using a validated direct observation system in addition to the rating scales may have identified a different sample of children or improved the description of the sample. Future studies with preschool age children may consider characterizing the child's perception (e.g., his or her stated intent) of the relationally aggressive act. A significant concern in understanding relational aggression in preschool age children is that, by definition, the actions are to intentionally damage or threaten to damage a relationship [34]. How that intention matures will be important to recognize in the context of tailored intervention. Similarly, it is important to comprehend the level of social competence that the child requires to execute his or her intentions [35].

Furthermore, the specifics of when and how relational aggression occurs need to be further documented. That is, the use, frequency, severity, and outcome of relational aggression among siblings in which there is no ability for either child to leave the relationship may vary substantially when compared to peer relations where, presumably, either of the children, could terminate the relationship [34]. Finally, how, when, and if relational aggression abates in children is likely also important for further intervention development.

\section{References}

[1] N. R. Crick, "Engagement in gender normative versus nonnormative forms of aggression: links to social-psychological adjustment," Developmental Psychology, vol. 33, no. 4, pp. 610617, 1997.

[2] N. R. Crick and J. K. Grotpeter, “Children's treatment by peers: victims of relational and overt aggression," Development and Psychopathology, vol. 8, no. 2, pp. 367-380, 1996.

[3] G. S. Rys and G. G. Bear, "Relational aggression and peer relations: gender and developmental issues," Merrill-Palmer Quarterly, vol. 43, no. 1, pp. 87-106, 1997.

[4] A. M. Remillard and S. Lamb, "Adolescent girls' coping with relational aggression," Sex Roles, vol. 53, no. 3-4, pp. 221-229, 2005.

[5] J. Archer and S. M. Coyne, "An integrated review of indirect, relational, and social aggression," Personality and Social Psychology Review, vol. 9, no. 3, pp. 212-230, 2005.

[6] S. M. Coyne, J. Archer, and M. Eslea, "'We're not friends anymore! unless...": the frequency and harmfulness of indirect, relational, and social aggression," Aggressive Behavior, vol. 32, no. 4, pp. 294-307, 2006.

[7] K. Keenan and D. Shaw, "Developmental and social influences on young girls' early problem behavior," Psychological Bulletin, vol. 121, no. 1, pp. 95-113, 1997.

[8] P. Silverthorn and P. J. Frick, "Developmental pathways to antisocial behavior: the delayed-onset pathway in girls," Development and Psychopathology, vol. 11, no. 1, pp. 101-126, 1999. 
[9] Q. Q. Tiet, G. A. Wasserman, R. Loeber, L. S. McReynolds, and L. S. Miller, "Developmental and sex differences in types of conduct problems," Journal of Child and Family Studies, vol. 10, no. 2, pp. 181-197, 2001.

[10] H. Xie, T. W. Farmer, and B. D. Cairns, "Different forms of aggression among inner-city African-American children: gender, configurations, and school social networks," Journal of School Psychology, vol. 41, no. 5, pp. 355-375, 2003.

[11] N. R. Crick, J. F. Casas, and H. C. Ku, "Relational and physical forms of peer victimization in preschool," Developmental Psychology, vol. 35, no. 2, pp. 376-385, 1999.

[12] N. R. Crick, J. F. Casas, and M. Mosher, "Relational and overt aggression in preschool," Developmental Psychology, vol. 33, no. 4, pp. 579-588, 1997.

[13] Crick N. R., J. M. Ostrov, K. Appleyard, Jansen E. A., and J. F. Casas, "Relational aggression in early childhood: "you can't come to my birthday party unless...", in Aggression, Antisocial Behavior, and Violence among Girls, M. Putallaz and K. L. Bierman, Eds., pp. 71-89, The Guilford Press, New York, NY, USA, 2004.

[14] J. M. Ostrov and C. F. Keating, "Gender differences in preschool aggression during free play and structured interactions: an observational study," Social Development, vol. 13, no. 2, pp. 255-277, 2004.

[15] J. M. Ostrov, K. E. Woods, E. A. Jansen, J. F. Casas, and N. R. Crick, "An observational study of delivered and received aggression, gender, and social-psychological adjustment in preschool: "this white crayon doesn't work ...",' Early Childhood Research Quarterly, vol. 19, no. 2, pp. 355-371, 2004.

[16] K. Stauffacher and G. B. DeHart, "Crossing social contexts: relational aggression between siblings and friends during early and middle childhood," Journal of Applied Developmental Psychology, vol. 27, no. 3, pp. 228-240, 2006.

[17] N. R. Crick and J. K. Grotpeter, "Relational aggression, gender, and social-psychological adjustment," Child Development, vol. 66, no. 3, pp. 710-722, 1995.

[18] S. E. Goldstein, M. S. Tisak, and P. Boxer, "Preschoolers' normative and prescriptive judgments about relational and overt aggression," Early Education and Development, vol. 13, no. 1, pp. 23-39, 2002.

[19] J. F. Casas, S. M. Weigel, N. R. Crick et al., "Early parenting and children's relational and physical aggression in the preschool and home contexts," Journal of Applied Developmental Psychology, vol. 27, no. 3, pp. 209-227, 2006.

[20] L. Bank, G. R. Patterson, and J. B. Reid, "Negative sibling interaction patterns as predictors Of later adjustment problems in adolescent and young adult males," in Sibling Relationships: Their Causes and Consequences, G. H. Brody, Ed., Ablex, Norwood, NJ, USA, 1996.

[21] A. Bandura, Aggression: A Social Learning Theory Analysis, Prentice Hall, Englewood Cliffs, NJ, USA, 1973.

[22] K. MacDonald and R. D. Parke, "Bridging the gap: parentchild play interaction and peer interactive competence," Child Development, vol. 55, no. 4, pp. 1265-1277, 1984.

[23] J. Dunn and N. Dale, "I a daddy: two-year-olds' collaboration in joint pretend play with sibling and with mother," in Symbolic Play: The Development of Social Understanding, I. Breterton, Ed., pp. 131-159, Academic Press, London, UK, 1984.

[24] K. Stauffacher and G. B. DeHart, "Preschoolers' relational aggression with siblings and with friends," Early Education and Development, vol. 16, no. 2, pp. 185-206, 2005.
[25] J. M. Ostrov, N. R. Crick, and K. Stauffacher, "Relational aggression in sibling and peer relationships during early childhood," Journal of Applied Developmental Psychology, vol. 27, no. 3, pp. 241-253, 2006.

[26] J. Archer, "Sex differences in aggression in real-world settings: a meta-analytic review," Review of General Psychology, vol. 8, no. 4, pp. 291-322, 2004.

[27] G. G. Tabachnick and L. S. Fidell, Experimental Designs Using ANOVA, Duxbury, Belmont, Calif, USA, 2007.

[28] N. R. Crick, "The role of overt aggression, relational aggression, and prosocial behavior in the prediction of children's future social adjustment," Child Development, vol. 67, no. 5, pp. 2317-2327, 1996.

[29] N. R. Crick, J. M. Ostrov, J. E. Burr, C. Cullerton-Sen, E. Jansen-Yeh, and P. Ralston, "A longitudinal study of relational and physical aggression in preschool," Journal of Applied Developmental Psychology, vol. 27, no. 3, pp. 254-268, 2006.

[30] N. R. Crick and A. J. Rose, "Toward a gender-balanced approach to the study of social-emotional development," in Toward a Feminist Developmental Psychology, E. K. Scholnick and P. H. Miller, Eds., pp. 153-168, Routledge, New York, NY, USA, 2000.

[31] A. Bandura, "Social cognitive theory: an agentic perspective," Annual Review of Psychology, vol. 52, pp. 1-26, 2001.

[32] M. A. McEvoy, T. L. Estrem, M. C. Rodriguez, and M. L. Olson, "Assessing relational and physical aggression among preschool children: intermethod agreement," Topics in Early Childhood Special Education, vol. 23, no. 2, pp. 53-61, 2003.

[33] K. A. Updegraff, S. M. Thayer, S. D. Whiteman, D. J. Denning, and S. M. McHale, "Relational aggression in adolescents' sibling relationships: links to sibling and parent-adolescent relationship quality," Family Relations, vol. 54, no. 3, pp. 373-385, 2005.

[34] A. D. Pellegrini and C. J. Roseth, "Relational aggression and relationships in preschoolers: a discussion of methods, gender differences, and function," Journal of Applied Developmental Psychology, vol. 27, no. 3, pp. 269-276, 2006.

[35] B. E. Vaughn and J. A. Santos, "Structural descriptions of social transactions among young children: affiliation and ominance in preschool groups," in Handbook of Peer Interactions, Relationships, and Groups: Social, Emotional, and Personality Development in Context, K. H. Rubin, W. M. Bukowski, and B. Laursen, Eds., pp. 195-216, Guilford, New York, NY, USA, 2008. 


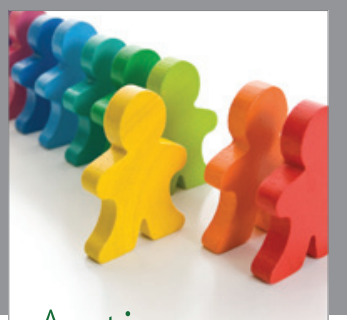

Autism

Research and Treatment
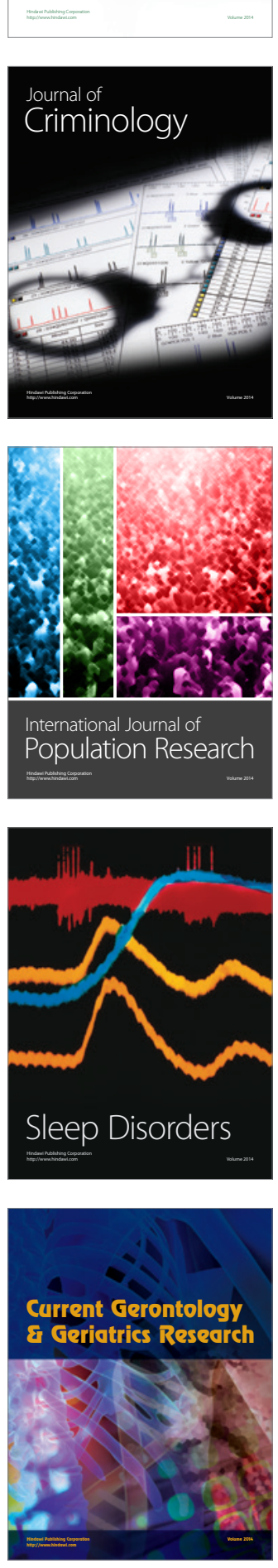
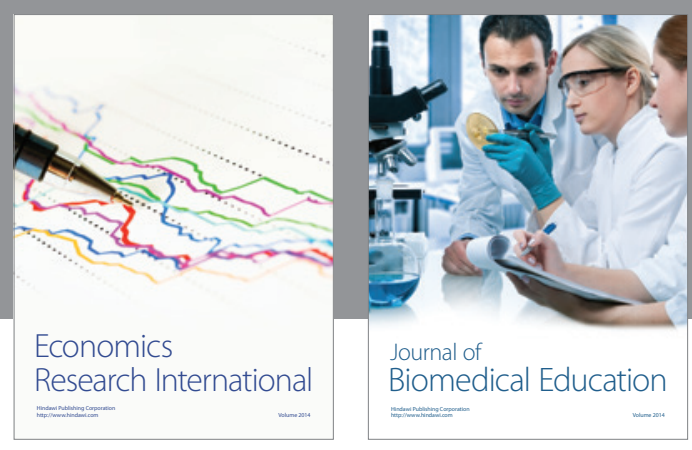

Journal of

Biomedical Education

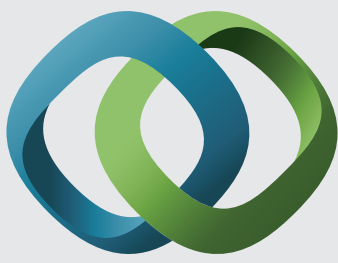

\section{Hindawi}

Submit your manuscripts at

http://www.hindawi.com
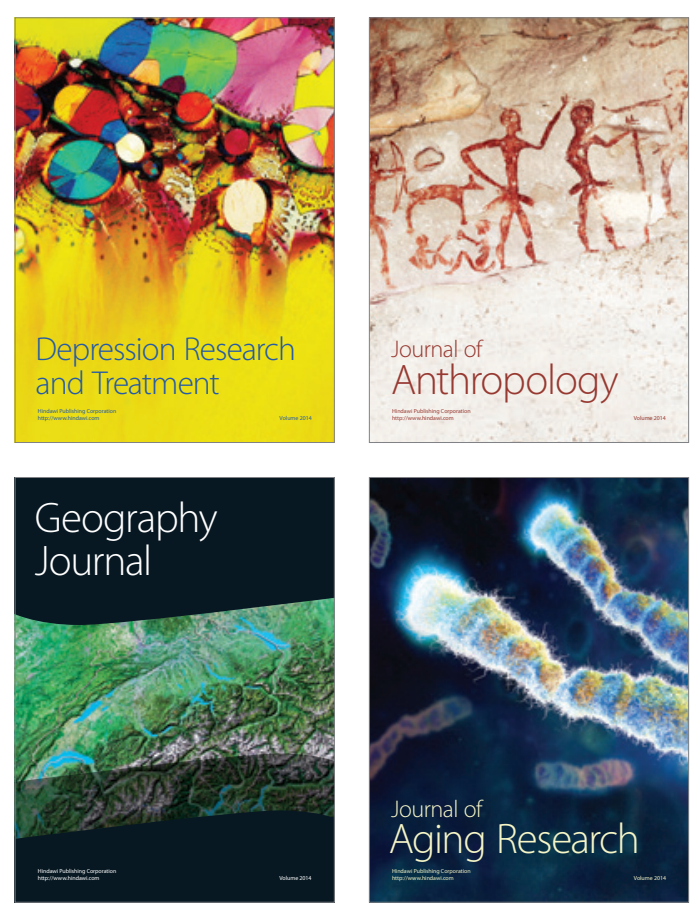

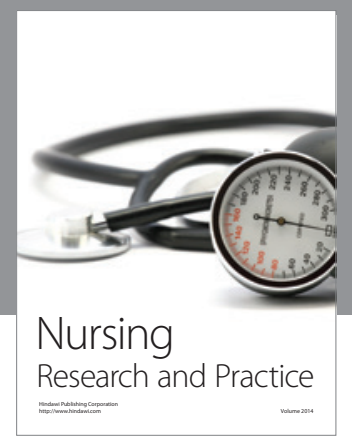

Nursing

Research and Practice

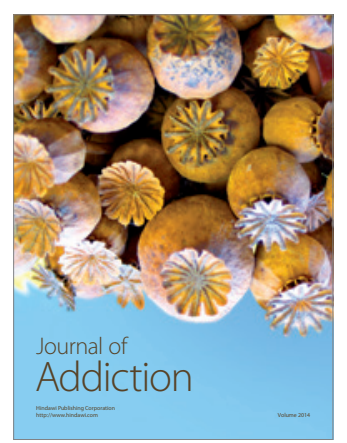

Child Development

Research

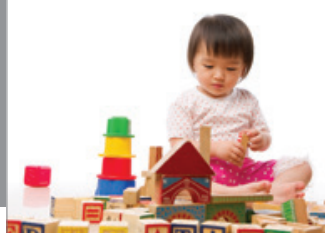

迥
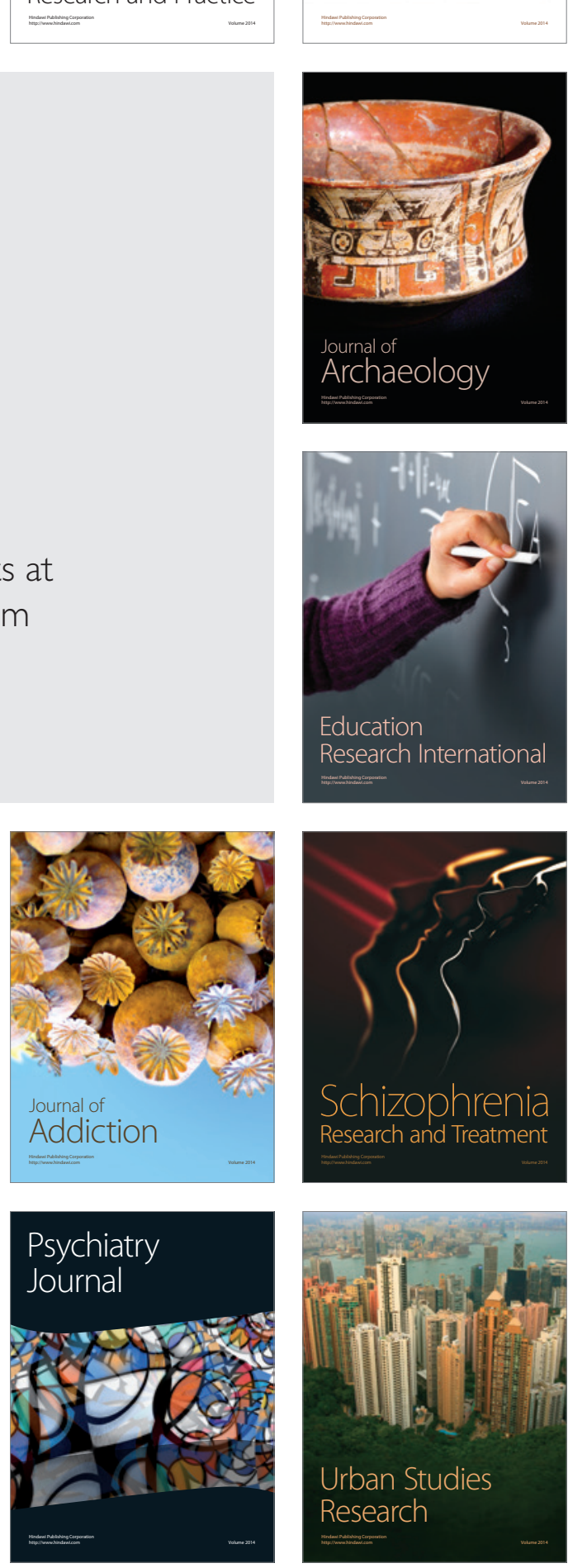